\title{
THE SQUARE HOUSE
}

Whatever be the merits of cubism in painting, there is much to be said for a return to it in domestic architecture. Artists. who have grown tired of the sinuous curves and soft shadows of accomplished art, have attempted to induce a quality of solidness by means of hard square shapes. Domestic architecture also has been suffering from, not indeed curves so much as odd ingles, nooks, corners, splayed coves, and other quaintnesses ; but whereas the reaction in painting is from over-refinement towards the direction of over-crudity, the architectural change suggested is of an opposite sort, that is to say, from the picturesque irregularities of rusticity to the severer refinement of a more highly civilised art. In fact, architecture is in this way, perhaps, the opposite of the other arts, in that the more square and simple it is, the more advanced its technique; whereas in painting and sculpture the same qualities generally denote the primitive and ruder stages. The square house, in fact, stands for advanced civilisation, but cubic painting for revolt against culture. Thus the affectation for a rustic type of house belongs really to the same wave of feeling which has produced much that is most striking in modern painting and sculpture ; it is difficult to give this movement a name which is wide enough in its scope, but one might roughly call it the Barbaric or Bucolic Heresy.

The same leaven working through the different arts, however, produces very different effects. For example, in sculpture this movement, if so it might be called, has suggested a return to primitive models, and by a fortunate chance the best exponents of it have turned for inspiration to archaic Greece and not to the Polynesian Islands, and this has produced finally noble art. One has only to look at the sculpture of Mestrovic or Mr. Gill to realise that this is no transition phase but an essentially modern treatment. In painting, with the exception of a few, whose return to simplicity led them to the first Italian painters of the school of Giotto, the result of this movement must be looked upon in the light of an artistic purge, something that will lead to a better state of health later on, by the sweeping away of the clotted humours, rather than producing any final great art in itself. Post-impressionism is thus a species of spring dosing with brimstone and treacle; a generally upsetting phase, but possibly leading to a state of fine condition for high summer. The two chief inspirations of this simplicity in painting have been the crude drawings of children and the daubing of savages; and certain artists have been also induced not only to imitate the technique of savages but actually to paint them as the best means of self-impression. 
In interpretive art the same phase is visible in the interest which has recently been aroused in folk songs and Morris dances, not only for their natural use by children but for grown-up people who are surfeited with the absolute refinement of the Russian ballet and the songs of Hugo Wolf.

\section{Bucolic Architecture}

The corresponding architectural simplicity was neither primitive Greek nor full-blown South-Sea-Island, but like the Morris dance, was taken from a Bucolic source; and it is to be feared that in it there was a similar lack of sincerity to that of the Parisian painter who felt that his emotions could only be expressed by painting South Sea Islanders. But it is necessary to part company with comparisons of the other arts, for architecture has to satisfy more widely different requirements than them and to adapt itself either to a homely utility and to the needs of an advanced modern civilisation. Thus one can hardly question the sincerity of the desire of a man, the greater part of whose life is spent under the urgently modern conditions of a town, to bury himself in the deserted country, once a year, and perhaps hire himself out as a voluntary day labourer on a farm. There may be affectation and self-consciousness about this, but there is no doubt that the type of house that a man during this bucolic recess would like to inhabit would be of rustic simplicity. One can imagine sanded floors, open chimney corners in which the hams were being smoked, small windows framed with jasmine, through whose thickly leaded panes it was hardly possible to see clearly, low ceilings and a thatched roof, appealing to him as an absolute relaxation from his normal existence. Some people are inclined even to go further and to undergo infinite hardships, acting the part of a man before the mast under conditions which would raise his utmost fury if by chance they happened unexpectedly on the way down to business; others voluntarily shun houses of any sort and camp out or trapse the countryside penniless as a tramp. This is an annual revolt against civilisation, and it is possible even to extend an understanding of the motive for revolt to the action of the few who retire permanently to live as a peasant among peasants. But this is a very different thing from the modern practice which is so common of attempting to combine rustic simplicity and rough homeliness of the country with an entirely modern urban occupation, at twenty minutes distance from the suburb. One cannot help feeling that this is crude artificiality, particularly when the husband is seen emerging from the rural cottage in a neat office suit and bowler hat. Perhaps the absurdity of this heresy was to be found at its highest pitch at Letchworth in the early days when this now serious industrial town 
was the haunt of the crank. There, were to be seen cottage doors made of a single board of elm, warping most horribly, door latches consisting of a bob of wood and string passing through a hole, gaping open hearths faced with roughest brick work, and the final touch of true affectation realised by the attempt to induce a house-leek torn from some ancient barn to grow on the tile roof of the new house. In at any rate one house in these early days it was possible to light upon a family entirely costumed in an antique manner out of due regard for their furniture. This was no doubt an extreme case, but the whole prevailing motif was what Sir Thomas Browne describes as "gross rusticity."

In characterising the picturesque type of house which has prevailed of recent years as rustic, and suggesting that there is a crudity about it, one does not by any means insinuate a contempt for the old manor house, its prototype ; an examination of almost any of these latter will show some delicacy of detail either around the porch or in moulded mullion and coping, together with a careful use of precious material such as finely chiselled stone, suggesting the solid life of the country gentleman of the seventeenth century. However, except for those precise and costly reproductions which are occasionally carried out in the country, the normal suburban house of this type has had to forego all these features on the score of expense and is left as merely a carcase stript of clothing. It is a somewhat similar state of affairs that would happen if we were to take a piece of Jacobean furniture and shave off its carving and moulded work, leaving the plain and rather clumsy bulk unrelieved. There are few people living in these suburban houses thus shorn of their details that would be willing consistently to use furniture with all enrichment planed-off, of the same period. In fact, furniture is a very good indication of the distance we have travelled from the seventeenth-century mode of living. Whether we buy old furniture, reproducts of old, or frankly modern, the greater part of it belongs to the latter part of the eighteenth century in its general characteristics, or at any rate in its economy in the use of wood.

\section{An Illogicality}

It is interesting to notice that in the case of most of the planning connected with the Garden City and Garden Suburbs this rustic charge cannot be made. Germans, with their intense scientific consistency and a strong inclination to revert not only to rustic models but also to mediæval, have pursued the movement to a logical conclusion by attempting to reproduce the vagaries of the old village and town plan, which they with their eager research have worked up into a serious æsthetic system under the guidance of Camillo Sitte. There is at any rate logic 
on their side, and the picturesque gabled house and rough cottage is spaced in hazardous disorder on streets that curve and wander for no apparent purpose; the thing is as well done as might be expected from such a thoroughgoing country, and one is occasionally led to think that one is walking in an old country town or mediæval city; but the very successfulness of this savours rather of the archæological reproductions which we associate with the old London or mediæval Paris section of an international exhibition.

We in this country have been inclined to look upon the garden suburb or village as an artificially and consciously modelled creation, and when the site is level have usually adopted a formal layout, allowing the regularities of a site alone to produce picturesque planning. We have considered that the old village street with its irregular widths and unexplained twistings is impossible of reproduction satisfactorily; but having rejected this mediæval reproduction in our plans, with a certain want of logic we have proceeded to fit on to them the country cottages of the sixteenth and seventeenth centuries, preserving though in a cheapened form their principal structural features, of long low casement windows, steep roofs, and frequent gables.

In itself, no one would at this period of the world's history set out to condemn anything by reason of its illogicality. A far more extraordinary case which no one would take exception to on this score was the entire divergence of views between the formal Town Planning of Haussmann and the picturesque irregular landscape treatment of Alphand for the gardens : the two opposite treatments used side by side have a certain amount of piquant contrast which one might urge in favour of the picturesque house on the formal plan. But there is always a feeling that in the picturesque treatment of architecture, the units in themselves must be sufficiently interesting and elaborated to command separate attention and study, such as is the case with the old picturesque town house of the South German towns. If a building whose main lines and shapes prevent the eye from passing on directly to its neighbour, arresting it in front of it, turns out on closer scrutiny, however, to contain little that is really of interest, there is a feeling of disappointment, of expectation not realised; and one is apt to suggest that if the same house instead of calling attention to itself, had been so designed that the eye had been led on to its neighbour and on again to some general street picture, there would have been some chance of compensating for the lack of interest in the individual house. In many of the old English country towns such groups of houses may be seen which present a charming effect together, whereas on analysis each one is found to be hardly worth separately sketching or photographing. It is this humble, perhaps, but 


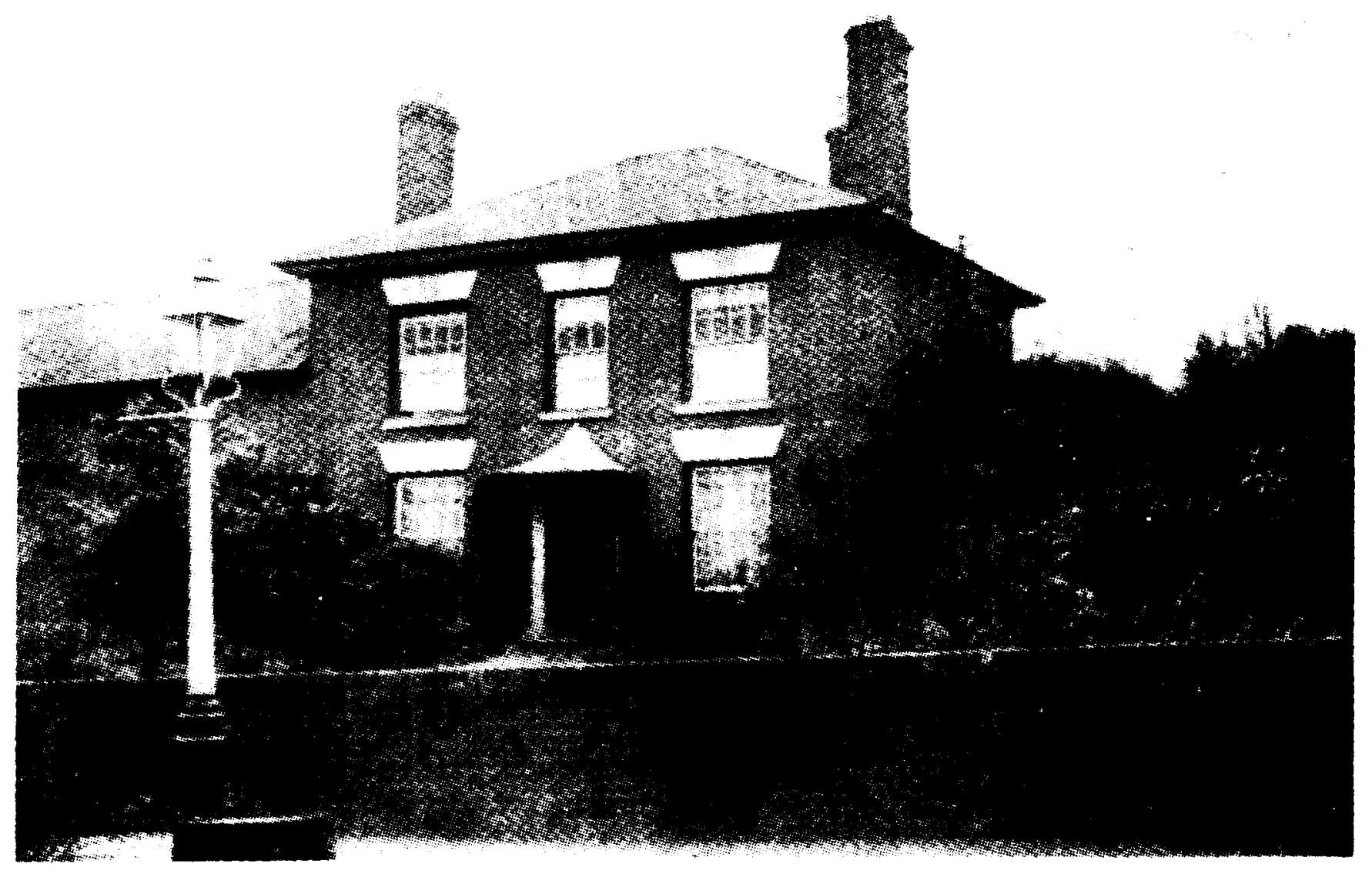

hOUSE AT THE HOMEND, LEDBURY

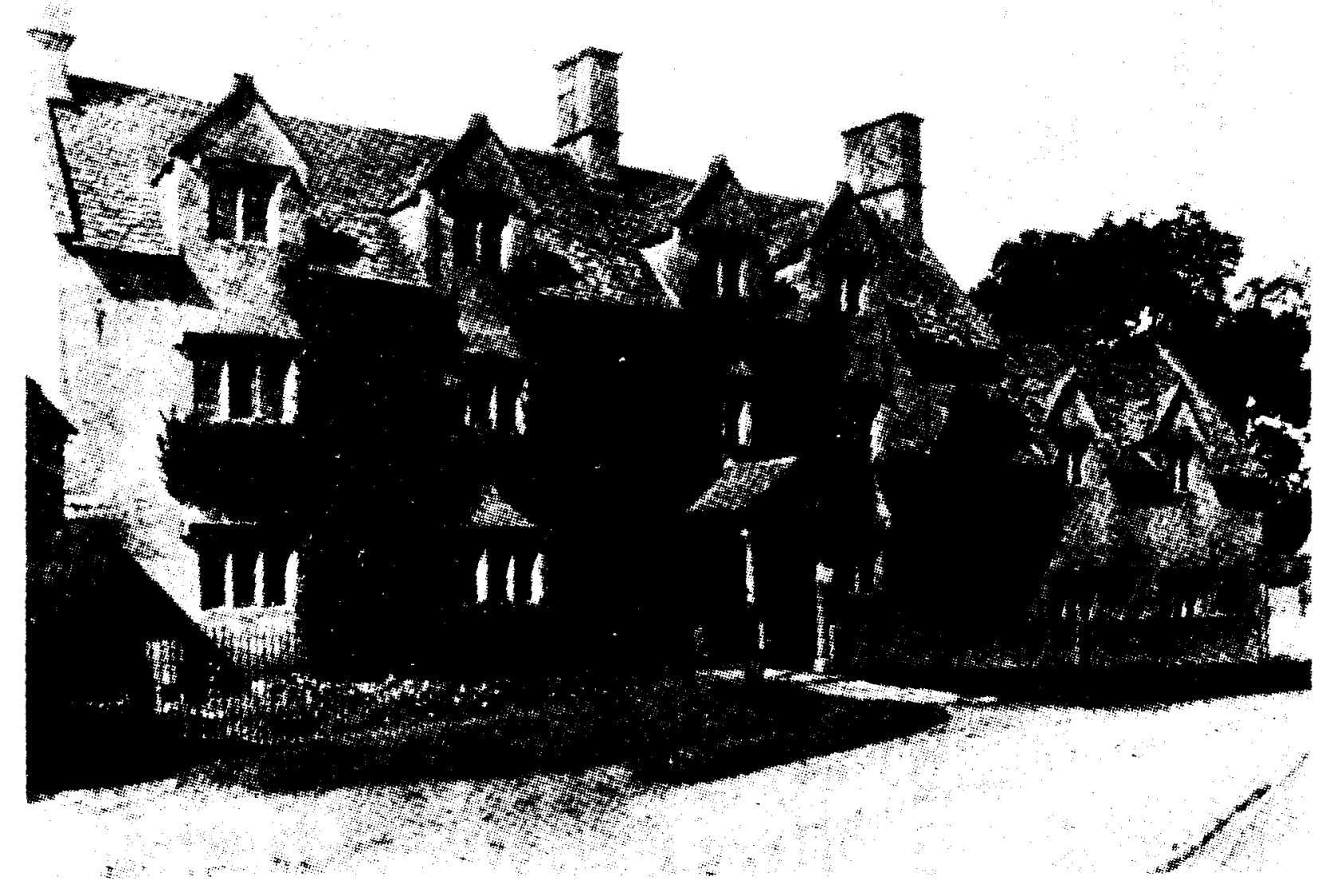

TUDOR HOUSE. MICKLETON

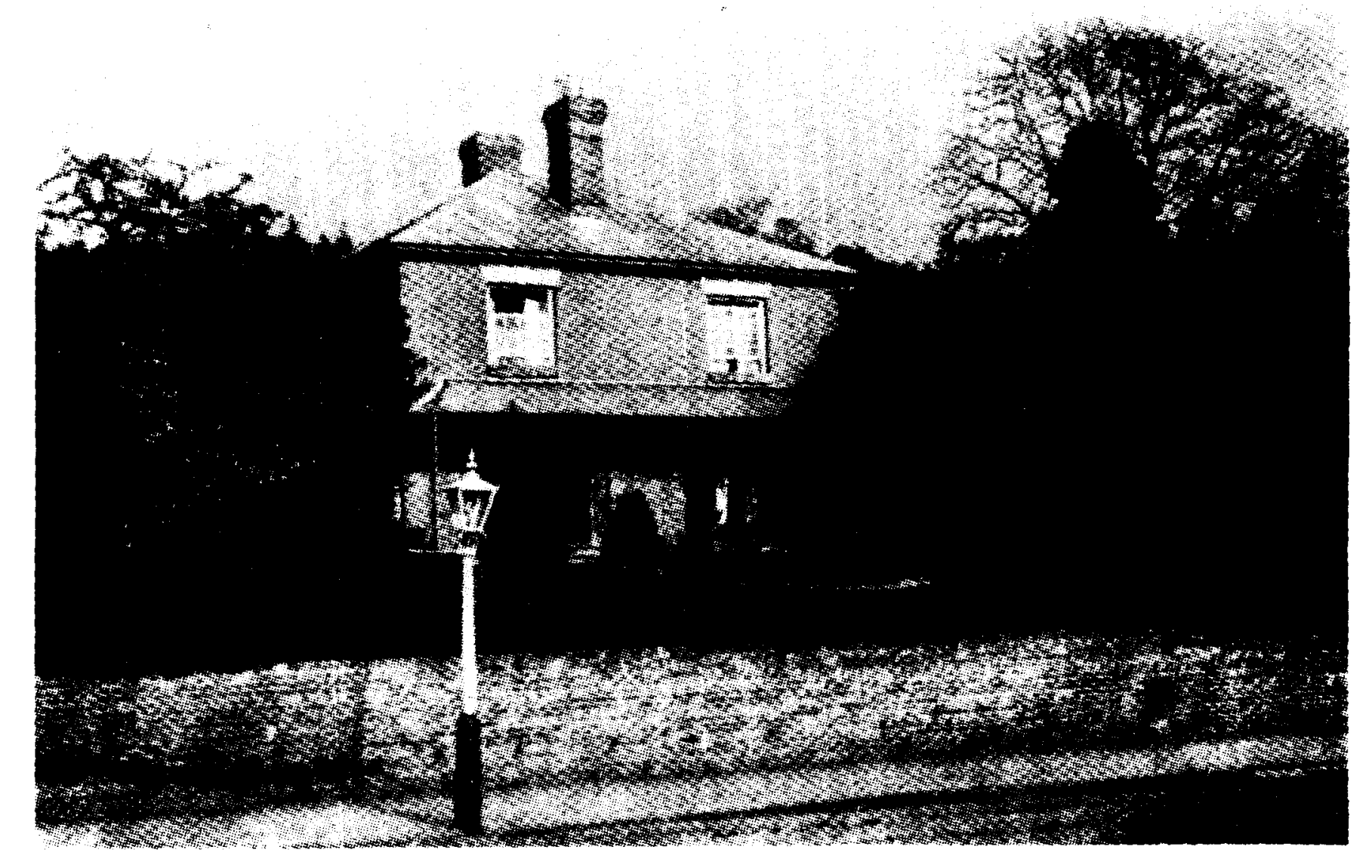

HOUSE AT THE HOMEND. LEDBURY

THE, SQUARE. HOUSE. 
valuable collective effect which the square house is able to produce, by reason of the strongly pronounced horizontality of its lines and the very modesty of its actual design.

One of the most evident examples of collective effect is to be seen in the little town of Newark-on-Trent. The Market Place, the street in front of the Castle, and that crossing the east end of the Church are all three lined with satisfying examples of square houses. In fact, the whole character of the town may be said to depend upon them, as unlike Tewkesbury, there are scarcely any of the half-timbered houses left to engross the attention of the tourist. At the same time, their very simplicity and quietness, and absence of elaborate architectural features render it extremely difficult to give any semblance of the effect of these houses in photographs; it is the accumulative effect which is so thoroughly satisfying. But how completely we have lost the appreciation of this charm, or rather, how thoroughly the typical architect has failed to analyse wherein it consists, is demonstrated in the most unmistakable manner near the Castle ; there may be seen on one side of the old Roman Fosse Way the sedate dignity of the old brick houses and inns, opposed by the thin and flashy trash of a modern temperance hall, and yet the latter by the very piling up of its features gives much more opportunity to the manufacturer of picture postcards.

\section{Some Superficial Drawbacks}

It must indeed be confessed that it is a practical drawback of the square house that it is difficult to convey its true effect either in photograph or sketch, and worse still on an architectural drawing. Relying as it does almost entirely on subtle proportion - the relation of window area to wall space, the simple grouping of its features, and to an equal degree on the perfection of its material and delicacy of its detail-it is impossible to indicate these adequately on an architectural drawing. A client having such a design presented to him is apt to think that it is not a design at all but merely a box of bricks, whereas gables and half-timbered work, or modelled plaster, make a brave show in a sketch design. The three examples here shown from the market town of Ledbury are typical of this practical drawback. As they exist in their bright-red bricks, grey slate roofs, wide-open windows, verandahs, and shutters, no one could fail to be pleasantly affected by them, though perhaps one would not pause in front of them in the same way that one is inclined to pause before the example of the other type, the Feathers Hotel in the same town, with its ornate front of timber work; but they certainly contribute no less than the hotel to the comfortable feeling of prosperity which that fox-hunters' town exudes. The larger house forms a fine feature at the 
entrance to the South End; it is a solid square block suggesting security and comfort, with its front door opening direct on to the street, and its nine-window front facing on an enclosed garden. The other two house s are simpler than this one and are an instructive contrast to the more modern residences that face them. The larger house is an example of one of the advantages which these square houses possess when they are once built, that their plain wall surfaces afford an admirable setting for creepers. To cover them up with uninteresting Irish ivy is a great mistake, but the more shrubby climbers, including wisteria and vine, can be trained up their walls without any fear of obscuring precious architectural features.

Another difficulty which has undoubtedly been against the widespread modern use of the square house up to the present is that, although it looks so simple, it is by no means easy to design. It is not by any means so difficult a task to pile on ornamental features, or to allow the vagaries of a plan to discover their own roof solution by means of irregular gables wherever necessary, as to model the plan that it may conform to a somewhat severe external arrangement. No clever bit of detail skilfully worked into the front could be made to detract the eye from some glaring awkwardness or frank ineptitude. Certainly the square house cannot be designed without a great deal of careful study of old examples, and success can hardly be arrived at without a considerable amount of practice in adapting the type for modern purposes, for it is no reproduction that is to be aimed at, but a development of the same intentions.

Again, while with unlimited funds it is easier to arrive at the picturesque confusion of the early houses rather than to achieve the refined severity of the later, it must yet be confessed that the picturesque if properly carried out is a much more costly affair. A comparison of the two houses illustrated on plate 11 is somewhat indicative of this, although the "Square House" in this case is by no means of the least expensive type (a simple overhanging eave such as the two smaller houses at Ledbury possess might have been substituted for the cornice and blocking course); but it will be seen that Jacobean House at Winchcomb requires moulded stone mullioned windows, moulded gables, string courses, detached columns to the porch, elaborate chimneys, and a complicated roof in order to arrive at its picturesque and charming effect. In the Ledbury house, if we except the cornice, there are none but the most inexpensive and necessary features, the wooden shutters and plain key blocks to the gauged brick heads producing an effect with the simplest means. To attempt to translate the Jacobean design into cheap materials and with an absence of all moulded work, as so frequently seen in our garden suburbs, is to produce a weakened and miserable travesty; 


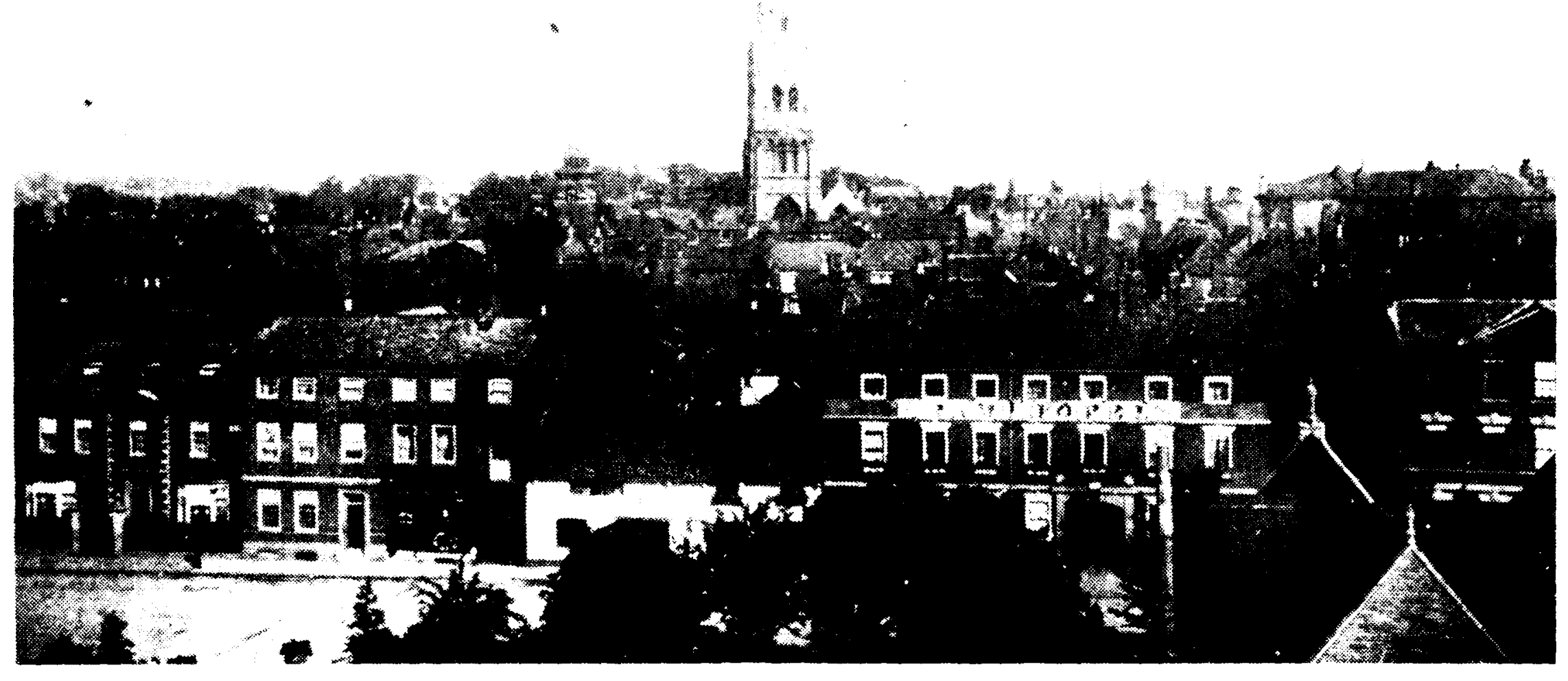

Old Houses facing the Castle

NEWARK-ON-TRENT

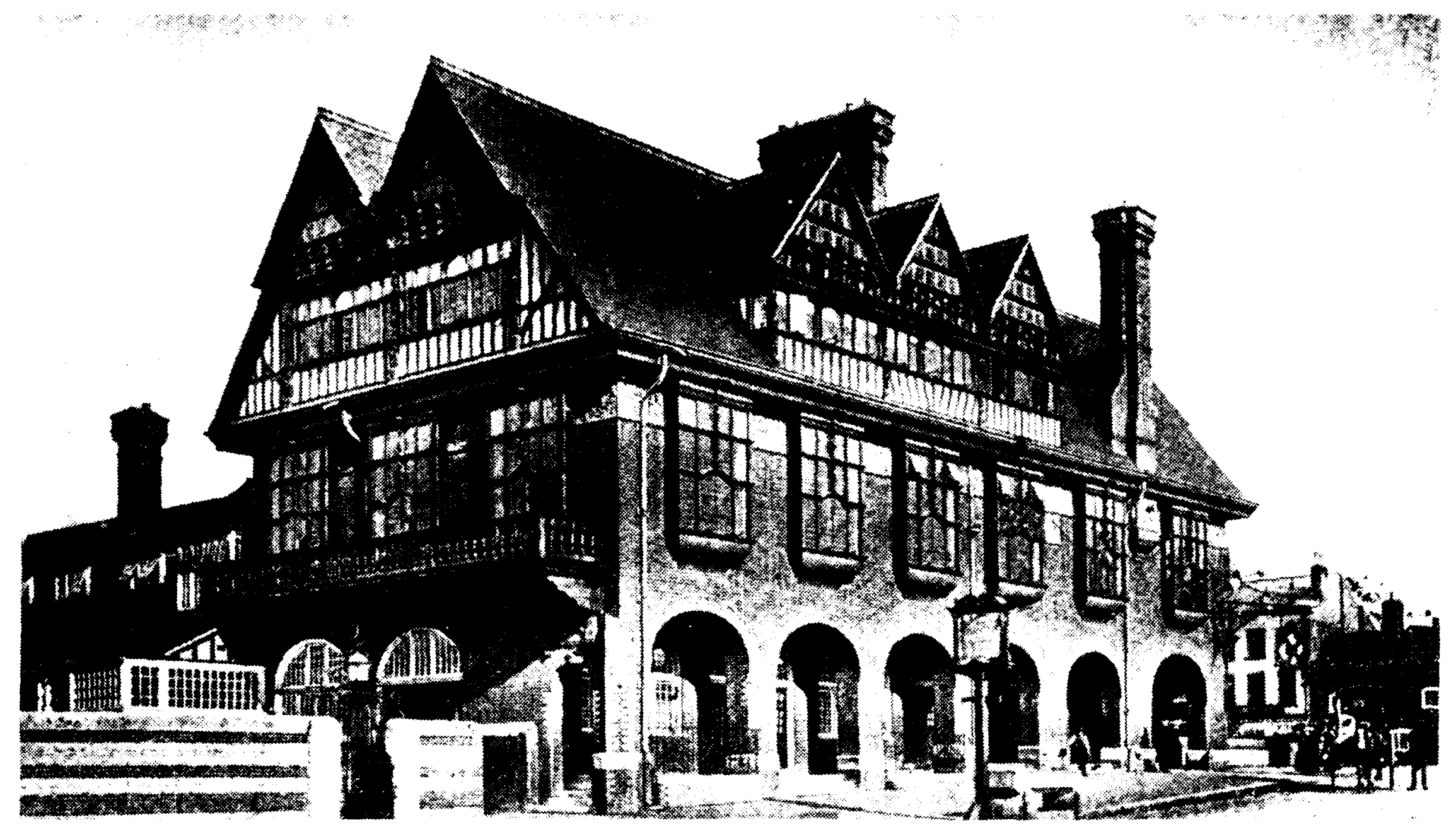

The New Coffee House

NEWARK-ON-TRENT

THE SQUARE HOUSE 
whereas the other house could be used as the basis of a modern design which had no less suggestion of comfort and refinement. Indeed, if the architect can give sufficient study, and bring sufficient skill to bear upon the problem, he can then produce inexpensive houses which are as dignified and solid as the old square houses. As a matter of fact, in saying that a picturesque type of design can let the solution of the roof discover itself, it must not be thought that this was the regular method with the Jacobean architects, who are frequently, as the house at Winchcomb shows, exceedingly careful to obtain a due balance to their fronts. This was, however, much more the case in the houses of the stone than

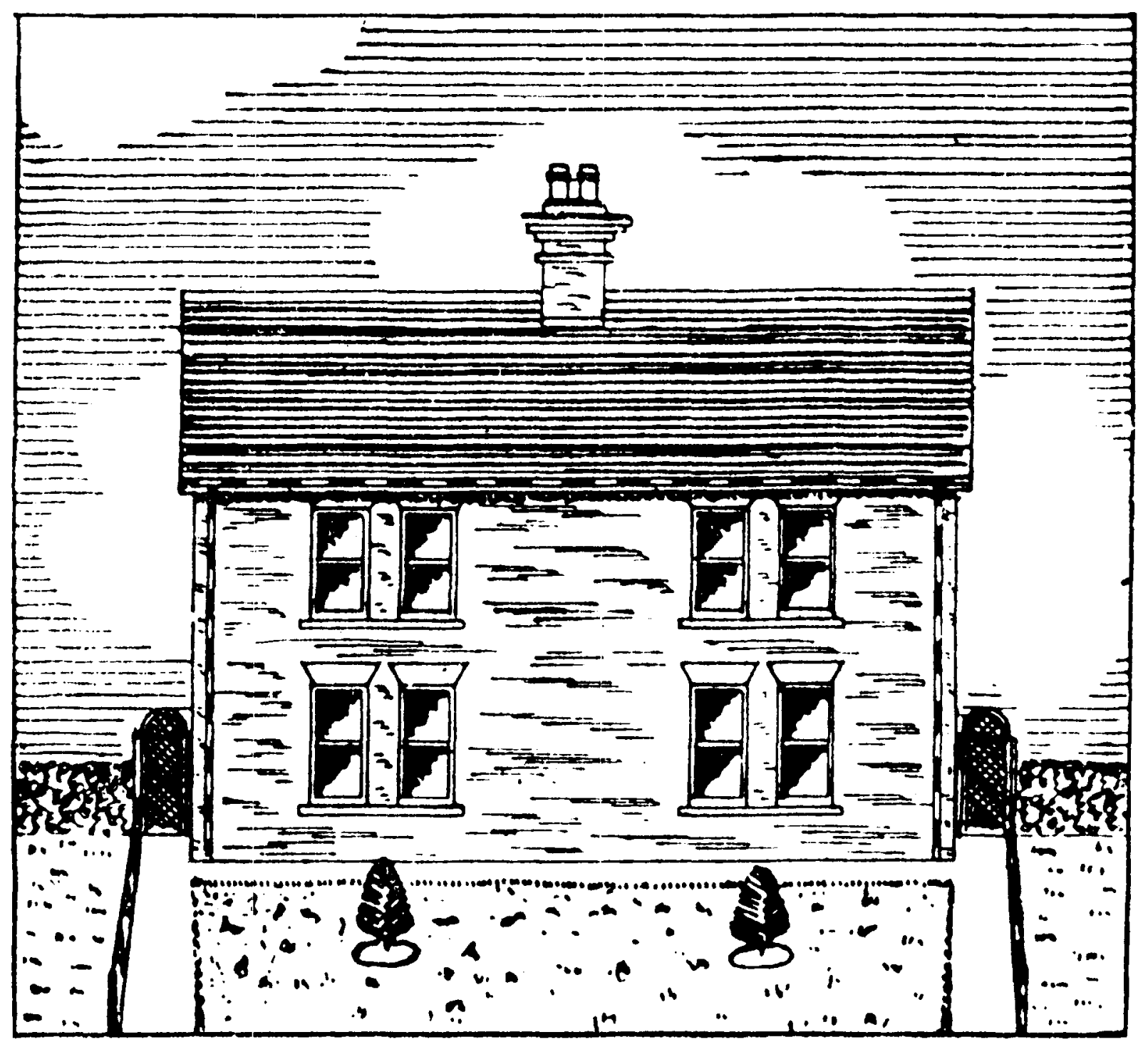

A depraved descendant of the Square House, which a Local Authority is proposing to erect and of which they have asked the Local Governinent Board to approve. in the timber-framed districts, the latter of which have been taken by the modern architect as the convenient models affording excuse for all his failures at symmetrical grouping.

One of the chief things to avoid in designing the square house is a certain clumsiness and heaviness which is very liable to creep in, particularly where the architect is not stinted in money, so that he may be tempted to employ full - blooded architectural features without realising "their impropriety. This fault is to be found in many of the early square houses that were built in the seventeenth century; the unnecessarily deep cornice, the over-emphasized doorway, the coarse window bars of some of these early examples, though they have a certain heavy richness about them, are yet little removed in refinement from the rustic type which has been already alluded to. Thus, whilst ample funds are necessary to the picturesque house, they are a temptation to the square house as regards its exterior; but the subtle architect need never be at a loss how to spend money on the interior.

There is a final drawback to the modern use of the square house; 
like all excellent things it is detestable in its corruption, and its corruption is unfortunately the typical square box of bricks with a slate lid that the Garden City movement set itself to destroy. A depraved and dissolute descendant of the old square house, with its door and windows like the mouth and eyes of the face hopelessly deformed in degeneracy, is with us everywhere-it is still built by local authorities anxious to house their poorest poor under circumstances which will successfully keep them submerged. Let no one thus confound so excellent a thing as the true Square House, that is to this, Hyperion to a satyr.

\section{The Sash Window}

Undoubtedly the most characteristic feature of the square house is the sash window, upon whose treatment depends its chief effect. The sash was brought over here from France, but soon after it was established in this country it was supplanted there by the French casement, which while giving the same proportion from an architectural point of view afforded a greater amount of ventilation. The sash window became identified with this country, whereas in France it is comparatively a rarity. With us there is not so much necessity as on the Continent to have an entire unobstructed open space for ventilation purposes, and it is without doubt by far the best type of window to withstand our peculiar form of bad weather, namely, driving moisture; the ingenuity of its device was certain of finding favour with us. It has two great practical advantages connected with its general shape. Its head can be taken close up to the ceiling, thereby securing efficient ventilation, and its cill can be brought down close to the floor, producing a cheerfulness of outlook. It can by being taken down to the actual floor be used as a garden door in the same way, although not quite as conveniently as a French casement. It is of course possible to get height of head and lowness of sill in mullioned windows by use of a transom, but this type of window is only suitable for larger houses. The typical window which has been so much made use of in the modern picturesque house is the long low casement shown in the Cotswold cottage at Mickleton on plate 12. However suitable this may be in the heart of the country, and however dear to those who wish to be carried back into the seventeenth century in their surroundings, it can hardly be contended that this shape of window is suitable to the modern suburban house. To be effective it must be kept down to a very definite size both as regards the width apart of the mullions and its height from cill to head.

But to the easy-going architect the sash is a dangerous instrument. He cannot use it at random, or in any variety of size to suit the requirements of rooms that happen to find themselves awkwardly on the main 
face of the building. Nor can it be considered the successful use of the sash window to plan a house in which a larder is lit by a gigantic window balancing that of a drawing-room ; modern architects have been known to fall into this error, which has the additional misfortune of bringing the sash into disrepute. Rather than do this they should stick to their picturesque casement, which has the advantage that it can be used almost anywhere and with unlimited variety as regards size, providing the sizes of its main units are preserved. In fact, if an architect has once got a casement right, it is comparatively difficult for him to use it wrongly,* but when he has proportioned a sash window correctly he is only at the beginning of his troubles; for the shape of the wall space between its neighbours on either side and its vertical relation to its fellows above and below are of equal importance. It might be urged that it is impossible to plan at all from modern requirements and use the sash window successfully; but this can hardly be substantiated, and it has been proved by actual experience to be incorrect. What it requires, however, is considerably more careful usage, and it will then amply repay labour that has been expended upon its use; whereas the mullioned window, which for the sake of economy has been carried out cheaply in wood instead of stone, thereby loses one of its chief attractions, that is to say, the continuity of wall and window surface which allows of its freer spacing. The only style in which the sash window has been used successfully in a picturesque and irregular manner is the Scottish Baronial, but it is to be hoped that no one will attempt to revive this style in England, and such attempts as have been made in Scotland can hardly be pronounced successful.

Other features connected with the square house, such as the roof, the shapes of its rooms, and its details, will be treated of in a subsequent part, and it is hoped to illustrate some further examples of this exceedingly simple but elusive style of house building.

Patrick Abercrombie.

\footnotetext{
* It will be almost invariably found that an unsuccessful Jacobean design is owing to the fact that the mullions are too wide apart, or some other defect in the proportion of the "unit" of window.
} 